\title{
A METHOD TO ESTIMATE THE LAND USE EFFICIENCY IN THE OLD CITY OF BEIJING
}

\author{
Jinxi Zhang ${ }^{1}$, Guoyin Cai ${ }^{1,2, *}$ \\ ${ }^{1}$ School of Geomatics and Urban Spatial Informatics, Beijing University of Civil Engineering and Architecture, Beijing, China; \\ 2529983537@qq.com \\ ${ }^{2}$ Beijing Advanced Innovation Center for Future Urban Design, Beijing University of Civil Engineering and Architecture, \\ Beijing 100044, China; cgyin@bucea.edu.cn
}

KEY WORDS: land use efficiency, old city, Sustainable Development Goal, population growth rate, building density growth rate

\begin{abstract}
:
The old city of Beijing represents the brilliant history and attracts people's attention worldwide. With the rapid development of urbanization in Beijing, the old city is facing the problem that more and more people are working or living in this limited region. How to estimate the land use efficiency in the old city is crucial for the city planners to perform some policy-making decisions. Based on the Sustainable Development Goal 11 (SDG 11) which is to develop inclusive, safe, resilient and sustainable cities and human settlements, in which indicator SDG 11.3.1 is designed to testify the land use efficiency that is defined as a ratio between land consumption rate to population growth rate(PGR).This paper focus on how to evaluate the land use efficiency in the old city where the land is limited to a region while people are in a continuous growing. Based on the extraction of buildings from high resolution images with sub-meter spatial resolution in the area enclosed by the second-ring road which is mainly consists of Dongcheng and Xicheng districts, this study obtained the 3D building information including building height and floor numbers over years from 2005 , 2010 to 2015 with the help of visually interpretation, POI information and the in situ investigation. By calculating the ratio of the building density growth rate(BDGR) to the population growth rate, the land use efficiency in the old city was computed for each year. Our results showed that most of the ratios are greater than 1 over year from 2005 to 2010 and less than 1 during periods from 2010 to 2015. Which means that the land use efficiency tend to lower from 2010 to 2015 than from 2005-2010. The reasons caused this phenomenon has been discussed in the discussion part. The results are helpful for local governors or managers to make a better decision in the protection and conservation of the old city, and to keep a sustainable old city.
\end{abstract}

\section{INTRODUCTION}

With the development of the economy and the increase of population, the urbanization of the country is developing rapidly. However, the historical city headed by Beijing faces a problem, that is, the land use efficiency of the old city is low, and the population is increasing. The old city needs to be reformed in a reasonable way[1]. The Old City of Beijing carries a large amount of tangible and intangible historical information. The Old City Residence is a witness and participant of its historical culture and the soul of the city. The old city of Beijing is the core functional area of the capital composed of Dongcheng District and Xicheng District. In 1955, Mr. Wu proposed the concept of "organic renewal": adopting appropriate scale and appropriate scale, and properly handling the relationship between the present and the future according to the content and requirements of the transformation. Recently, the United Nations Sustainable Development Summit adopted a new framework and entitled as "Transforming our world: the 2030 Agenda for sustainable development" to guide the development between 2015 and 2030[2]. This 2030 Agenda contains 17 Sustainable Development Goals (SDGs), one of the goal: SDG 11, known as "urban SDG", aims to "Make cities and human settlements inclusive, safe, resilient and sustainable"[3]. There are 10 targets and 15 indicators in SDG 11. Out of the 15 existing indicators, 6 are to be collected at local city level, such as 11.3.1 land consumption, 11.3.2 civil society participation, 11.5.1 budget on cultural heritage, 11.6.1 soildwaster, 11.6.2 air quality and 11.7.1 public space[4]. Population growth and increased per capita consumption are key drivers[5,6]. The SDG 11.3.1 indicator is intended to demonstrate land use efficiency, which is defined as the effect of the ratio of land consumption rates on population growth rates. However, because this study is about the old city, the land is limited to one area, so it is necessary to grasp the development status and land use of the old city[7]. Building density is an effective research indicator. Building density, also known as building coefficient, refers to the ratio of the total base area of the building to the land area within a certain land area, which is an important indicator reflecting the land use intensity, it can visually reflect the open space rate and building intensity of a certain area. For a region, high building density indicates that the land resource utilization intensity in this region is large, but too high building density will bring a series of ecological and environmental problems, resulting in unreasonable land use[8].

In the past, the study of building density was only for this aspect, and the results were limited. Therefore, this paper combines high-resolution satellite image and land cover products to calculate the ratio of building density growth rate to population growth rate in Beijing's old city, and to study the land use efficiency between 2005 and 2015. Although this method is different from the method mentioned in SDG 11.3.1, I think it can reflect the real land use efficiency of the area when studying the constant area of the old city.

\footnotetext{
* Corresponding author
} 


\section{METHODOLOGY}

\subsection{Study Area}

Beijing's Dongcheng District and Xicheng District are the core functional areas of the capital and the strongest downtown area among major cities in China. In terms of the pattern, Beijing's Dongcheng District and Xicheng District are the gathering places of Beijing and even China. In essence, Beijing's Dongcheng District and Xicheng District, as the core functional areas of the capital, are powerful downtown areas with the characteristics of the Chinese capital. The total area of Dongcheng District and Xicheng District is only 92 square kilometers. The proportion of Beijing is less than six thousandths, but the resident population is 2.213 million, accounting for $10 \%$ of the permanent population in Beijing. At the same time, because Beijing's large number of tourist attractions are also concentrated in the Dongcheng District and Xicheng District, the population density is much larger than other urban areas. Due to the old town, there are many old buildings and historic buildings. Therefore, land use efficiency is also low. Figure 1 is the study area of this study.

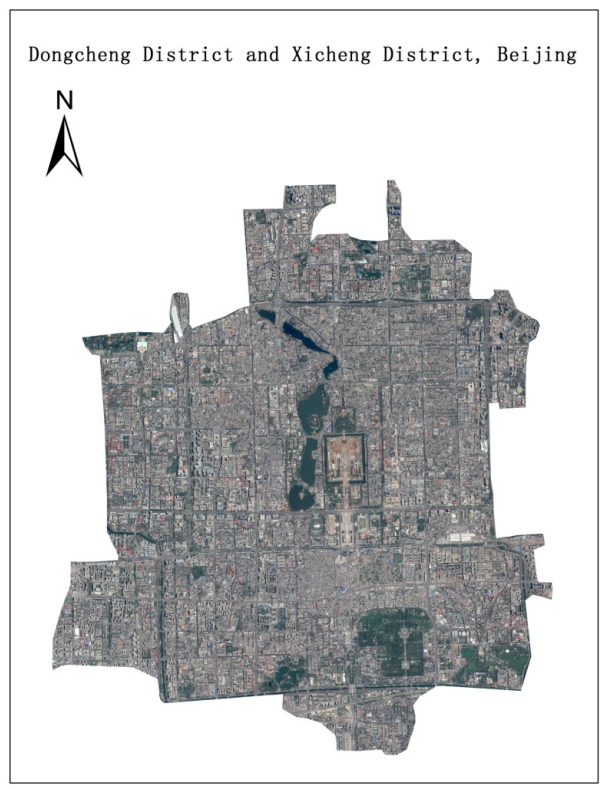

Figure 1. Study site

\subsection{Data Sources}

This study is based on all the buildings in Dongcheng District and Xicheng District of Beijing. The research includes various data related to Dongcheng District and Xicheng District of Beijing. The urban remote sensing image data is high-resolution image data with a spatial resolution of $0.5 \mathrm{~m}$ in 2005, 2010 and 2015. The GF-2 satellite is the first civil optical remote sensing satellite independently developed by China with a spatial resolution better than 1 meter. It is equipped with two highresolution $1 \mathrm{~m}$ full-color, $4 \mathrm{~m}$ multi-spectral cameras with submeter spatial resolution. High positioning accuracy and fast attitude maneuverability, which is the highest resolution civilian land observation satellite in China. The population data for 2005, 2010 and 2015 and the urban area data are from the 2005-2015 Beijing Statistical Yearbook.

\subsection{Methods}

The method for calculating indicator SDG11.3.1 is presented in the SDG indicators Metadata Repository managed by UNDESA (https://unstats.un.org/sdgs/metadata). SDG 11.3.1 is categorized as Tier 2 indicator which means that this indicator is conceptual clear and calculation method established, but data is not easily available. SDG 11.3 .1 is defined as the ratio of land consumption rate to population growth rate to indicate the land use efficiency with the rapid development of urbanization around the world $[9,10]$. Because the calculation method has been established and the indicator concept is clear, the method used in this paper draws on the method of calculating SDG11.3.1, which is defined as the ratio of building density growth rate to population growth rate to show that with the rapid development of the economy. , the land use efficiency of the old city of Beijing.

\subsubsection{Population Growth Rate(PGR)}

PGR is depicted as the increase of population in a given spatial unit over a time span. It reflects the number of births and deaths during a period and the number of people migrating to and from a given spatial unit, such as a country or a city.

The calculation of PGR is expressed as:

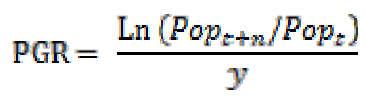

(1)

Where $\mathrm{Ln}$ is the natural logarithm, Pop ${ }_{\mathrm{t}}$ is the total population within the city in the initial year; Pop $_{t+n}$ is the total population within the city in the final year; $y$ is the number of years between the two measurement periods.

\subsubsection{Building Density Growth Rate(BDGR)}

BDGR is defined as the ratio of the total base area to the land area of all buildings in a given space over a period of time, reflecting the open space rate and building intensity of an area. The calculation of LCR is expressed as:

$$
\mathrm{EDGR}=\frac{\operatorname{Ln}\left(B \mathrm{ui}_{l+n} / \mathrm{Bui}_{l}\right)}{y}
$$

where $\mathrm{Bui}_{\mathrm{t}}$ and $\mathrm{Bui}_{\mathrm{t}+\mathrm{n}}$ is the Urban building density for the initial and the final year respectively; Ln and y represent the same mean as in equation (1).

2.3.3 Ratio of building density growth rate to population growth rate(BDGRPGR)

BDGRPGR is a ratio that quantifies the use of urban land surface, The estimate of the LCRPGR is expressed as:

$$
\text { BDGRPGR }=\frac{B D G R}{B G R}=\frac{\operatorname{Ln}\left(B_{\text {uii }}+n / B \text { ui }_{\tau}\right)}{\operatorname{Ln}\left(\text { Pop }_{t+n} / \text { Pop }_{t}\right)}
$$

\section{RESULTS}

This experiment calculates the land use efficiency of the old city based on the calculation method mentioned above. 


\subsection{Building density in the old city of Beijing}

Dongcheng District covers an area of 41 square kilometers and Xicheng District covers an area of 50.70 square kilometers. The land use data from 2005 to 2015 was extracted through data processing, and the vector data of the construction land in the old city was obtained(Figure 1), Statistics show the area of construction land for the three years(Figure 2), Thus the building density of the two urban areas in three years(Table 1).

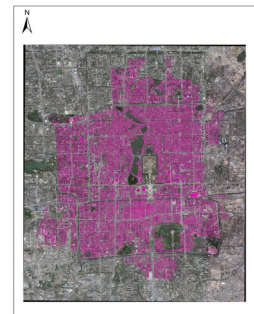

2005

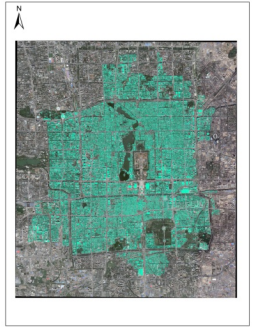

2010

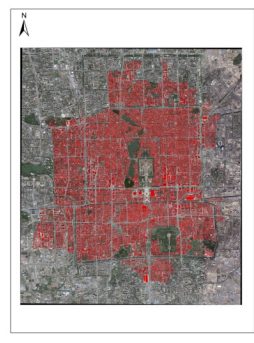

2015
Figure 1. Building lands in old city from 2005 to 2015 with an interval of 5 years

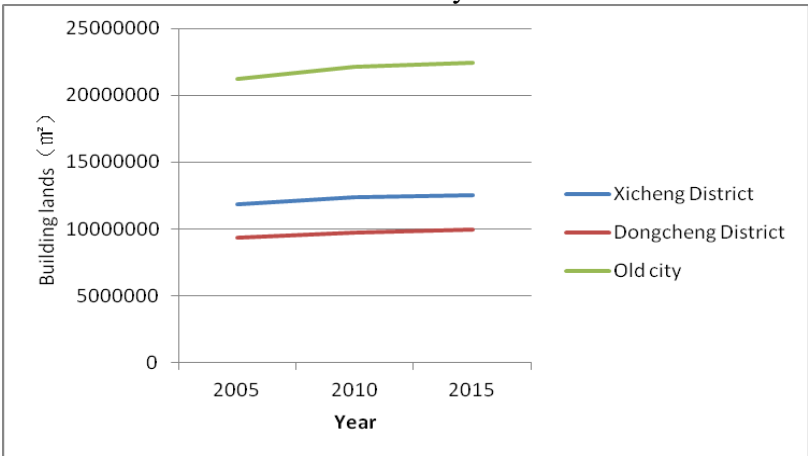

Figure 2. Change of building lands in Old city over years from 2005 to 2015

\begin{tabular}{|l|c|c|c|}
\hline Years & \multicolumn{3}{|c|}{ Building density (\%) } \\
\hline & $\begin{array}{c}\text { Dongcheng } \\
\text { District }\end{array}$ & $\begin{array}{c}\text { Xicheng } \\
\text { District }\end{array}$ & Old city \\
2005 & 22.80 & 23.36 & 23.11 \\
2010 & 23.76 & 24.37 & 24.10 \\
2015 & 24.21 & 24.68 & 24.47 \\
\hline
\end{tabular}

Table 1. Building density of each district

It can be seen from Figure 2 that from 2005 to 2015, the area of construction land in the old city of Beijing increased, from 21.19 square kilometers in 2005 to 22.44 square kilometers in 2015. It can be seen that the growth rate of construction land from 2010 to 2015 is not as large as that from 2005 to 2010 . From 2005 to 2010 , it can be clearly seen that due to the rapid economic development, urban construction is also being built. The slowdown in the increase in construction land after 2010. This can also reflect the adjustment of Beijing's construction in recent years.

\subsection{Population Growth}

The population data is the resident population from the yearbooks of various years in Beijing. Although the population of the old city is on the rise as a whole, the growth trend from 2005 to 2010 is even higher, and the population of the old city has increased by 110,000 . The population growth trend from 2010 to 2015 has slowed down, and the total population has increased by 40,000. From 2013, the population of the old city has also decreased(Figure 3). Compared with the continuous increase in construction land, the population of the old city has decreased in a certain year. This phenomenon of population decline is related to plans and policies for evacuating people in Beijing. The most critical of these is the ban on building homes in Dongcheng District and Xicheng District, which echoes the results obtained above.

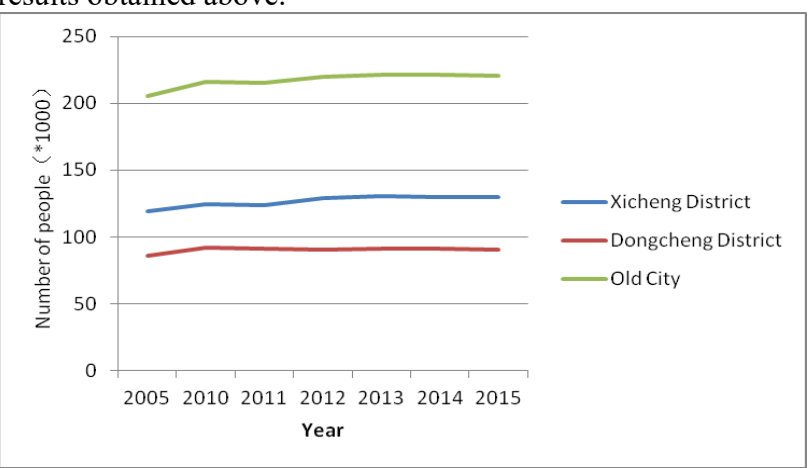

Figure 3. Change of population in Old city over years from 2005 to 2015

\subsection{Ratio of BDGR to PGR}

The population data was statistically compuated with a spatial unit of townships over years from 1990 to 2015 with a 5 years interval. Based on the collected township vector data and the extracted build-up lands in Beijing old city, the area of build-up lands has been calculated over years from 2005 to 2015 with a 5 years interval. Based on equations (1-3), the values of BDGR, PGR and BDGRPGR have been calculated in a spatial unit of old city in Beijing(Figure 4). Overall, compared to BDGR and PGR, BDGRPGR showed little change between 2005 and 2015, while both BDGR and PGR showed a downward trend. However, from Dongcheng District and Xicheng District, the three indicators of Dongcheng District have shown a downward trend, but the PGR of Xicheng District has a slight increase.

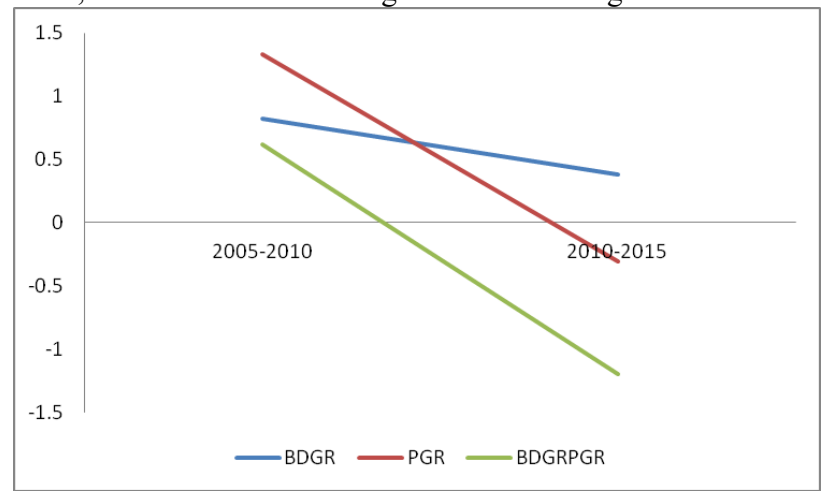

Dongcheng District

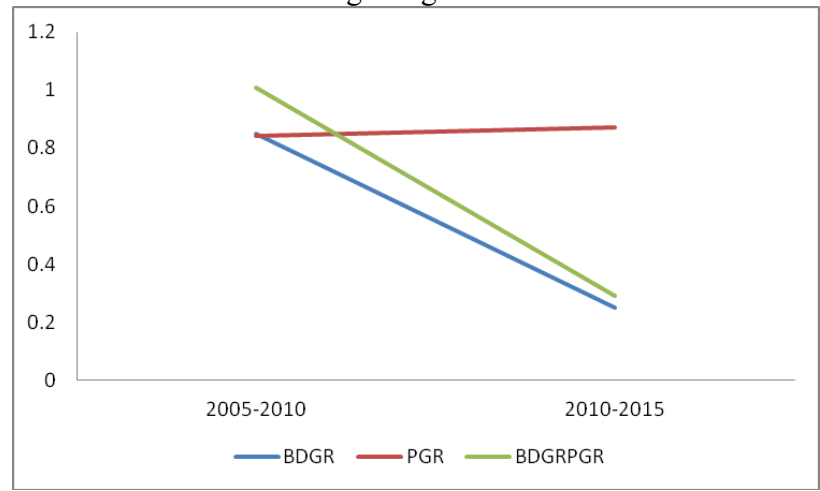

Xicheng District 


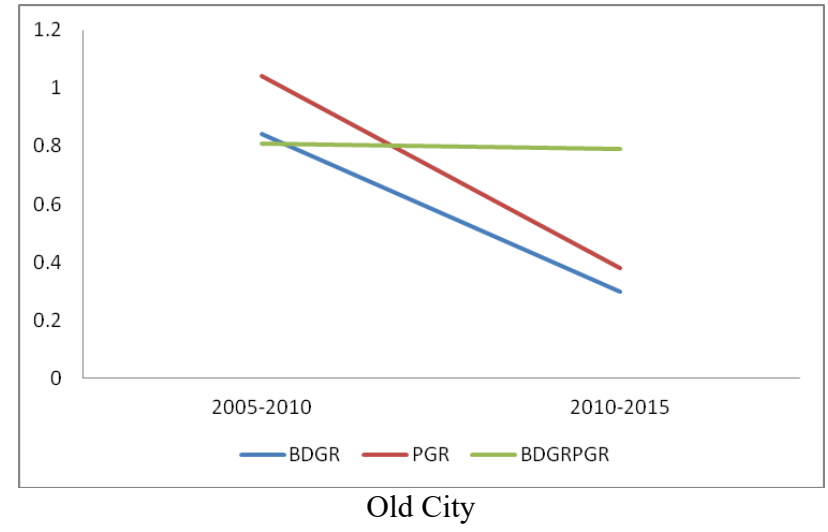

Figure 4. BDGR, PGR, BDGRPGR curves over years from 2005 to 2015 with 5 years interval.

The average BDGRPGR of the old city of Beijing is 0.79 , which means that the building density growth is 0.79 times as quick as the population growth. Between 2005 and 2010, all values in any urban area were around 1 . And by 2010 to 2015. The population of Dongcheng District has even decreased, so the PGR is negative. In addition, the population growth rate of Xicheng District increased slightly from 2010 to 2015 compared with 2005 to 2010 . From overall view. The three values of the old city are reduced, but compared to BDGR, the decline of PGR is always inferior to BDGR. This shows that Beijing's old city is managing building growth and has achieved remarkable results in controlling the use of construction land, but it still needs to continue its efforts in population control. However, this is also a common problem in the old city. How to solve the growing problem of living and the improvement of quality of life on limited land, the relevant departments of Beijing need to continue to explore.

\section{DISCUSSION}

High resolution satellites and the land cover products prove a high quality data resources for the information of build-up lands to calculate the land consumption. Two different types of data sources were combined together in this study to extract the build-up lands over years from 2005 to 2015 with an interval of 5 years. The geographical conditions data reflects the true land cover/land use status with a very higher accuracy. It plays a key role in obtaining the build-up lands in different periods of time span. Because of the uncertainty in information extraction from satellite images, it needs more time to integrate data from different data sources and manually edit to ensure that the finally extracted build-up lands in different years keep spatially consistent. The population data we used is the resident population data of Beijing. Because of the population flow is a common phenomenon in China, the resident population is the best choise to analyze the land use efficiency. However, for Beijing, as a capital city, the tourist city will have more floating populations per year, so the land use efficiency calculated in this study is higher than the real result.

\section{CONCLUSIONS}

Solving the problems in the old city is a trend in the current and subsequent years, especially in Beijing, Nanjing, Xi'an and other historical cities. SDG 11.3.1 was designed to calculate the efficiency of urban land use as a consequence of population growth. This article draws on SDG11.3.1 and introduces building density in conjunction with its own understanding. The conclusions from a case study of the old city of Beijing, can be drawn as follows:
Satellite imagery and the land cover products provide a reliable and long-term data sources to calculate the building density and land use efficiency over years. Although this experiment is only an attempt, it can be used as a reference for others to continue to study the issue of land use efficiency in the future.

By combining spatial data and statistical data, land use efficiency can be quantitatively identified. In general, from 2005 to 2015, the land use efficiency of the old city of Beijing was basically flat, with a small decline, but this is quite difficult. The land use efficiency of Dongcheng District is better than that of Xicheng District as a whole.

\section{REFERENCES}

F .Frederic Deng, Youqin Huang., 2004. Uneven land reform and urban sprawl in China:the case of Beijing[J]. Progress in Planning, 61:211-236.

Nations, U., 12 October 2015. Critical milestones towards a coherent, efficient, and inclusive follow-up and review of the 2030 Agenda at the global level.

Satterthwaite, D., 2013 Urban Poverty in the Global South: Scale and Nature, Routledge London.

UN-Habitat., 2018. A guide to assist national and local governments to monitor and report on SDG goal 11+ indicators.

Wang, J.;Dong, K., 2019. What drives environmental degradation? Evidence from 14 Sub-Saharan African countries. Science of The Total Environment. 656, 165-173. doi:10.1016/j.scitotenv.2018.11.354.

Rehman, M.;Rashid, M., 2017. Energy consumption to environmental degradation, the growth appetite in SAARC nations. Renewable Energy, 111, 284-294. doi:10.1016/j.renene.2017.03.100.

Xiaolu Gao , Yasushi Asami, Wataru Katsumata et al., 2006. Evaluating land-use restrictions concerning the floor area ratio of lots.Environment and Planning, 24:515-532.

Chen Ying, Liu Kang, Zheng Weiyuan et al., 2002. Evaluating land use intensifi cation potential in urban area:its implications for practical land administration[J]. China Land Science, 16(4):26-29.

Melchiorri, M., Pesaresi, M., Florczyk, J. A., Corbane, C.;Kemper, T., 2019. Principles and Applications of the Global Human Settlement Layer as Baseline for the Land Use Efficiency Indicator-SDG 11.3.1. ISPRS International Journal of Geo-Information, 8, 96. doi:10.3390/ijgi8020096.

Schneider, A. Woodcock, C. E., 2008. Compact, Dispersed, Fragmented, Extensive? A Comparison of Urban Growth in Twenty-five Global Cities using Remotely Sensed Data, Pattern Metrics and Census Information. Urban Studies, 45, 659-692, doi: $10.1177 / 0042098007087340$. 